\title{
Application of IRNDT method for materials in wide range of thermal diffusivity
}

\author{
by Z. Veselý*, M. Švantner*
}

\begin{abstract}
* University of West Bohemia, New Technologies Research Centre, Univerzitni 8, Pilsen, Czech Republic,
\end{abstract} zvesely@ntc.zcu.cz, msvantne@ntc.zcu.cz

\begin{abstract}
Infrared non-destructive testing method (IRNDT) is suitable supplement to classic non-destructive testing methods (NDT). The advantage of IRNDT method is fast and non-contact measurement and evaluation that is available to various industrial and research applications. The method is suitable for both production process inspection (material inhomogeneities, inner structure of multilayer parts, cracks, ...) and subsequent component inspection during service (cracks, layers delamination, etc.) The possibility of defects detection is influenced by IRNDT method parameters, geometric orientation of defects and by physical properties of material. The influence of material thermal properties on the detectability of defects is discussed.
\end{abstract}

\section{Introduction}

Infrared thermography can be classified as passive or active. Passive thermography means infrared measurement of object under natural conditions while active thermography involves infrared measurement after prior thermal excitation of the analyzed object. Infrared non-destructive testing method [1-3] belongs to the active thermography. It is used for defects detection in the material. The detectable defects are only those influencing the heat transfer in the object - material inhomogeneities, voids in the material, cracks or delaminated layers for example. Thus the infrared non-destructive testing method can be used for input and output inspection of products during the manufacturing process. The IRNDT method is also usable for identification of internal structure of non-homogeneous materials. The efficiency of defect detection depends on their geometrical orientation, on the parameters of thermal excitation (pulse power, pulse length and number of pulses) and on thermal properties of the tested material.

The advantages of IRNDT method are non-destructive non-contact testing, speed of inspection, wide range of industrial and research applications and the usability for wide range of materials. The necessary conditions for IRNDT testing method are homogeneous thermal excitation of whole inspected surface, limited inspection depth combined with defects size and elimination of reflections from surrounding and/or thermal excitation source directly to the detector of IR camera. According to the application, a suitable combination of excitation method, analysis method and evaluation method including their parameters has to be found [4-7].

This work is concerned on the influence of thermal properties of basic material on the ability of defects detection, i.e. on the size and depth of distinguishable defects.

\section{Experimental procedure}

In the IRNDT method, the proper homogeneous thermal excitation of whole analyzed surface of the object is important. It has been provided by direct heating using a flash lamp or halogen lamps. Laboratory and industrial flash lamps (Fig. 1a,b) produce intensive and very short (ms) pulses. The halogen lamps (Fig. 1c) create longer (s) pulses. When the direct heating excitation source is applied, the defects detectability depends on their orientation with respect to the direction of heat flux in the material.

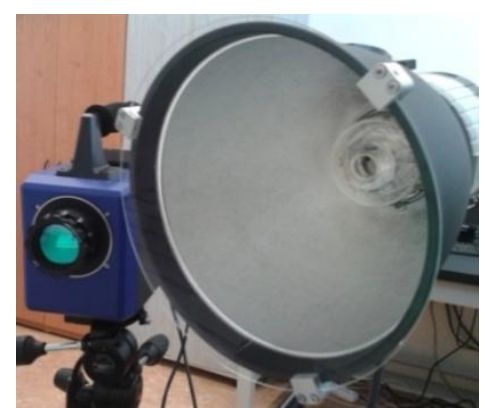

(a)

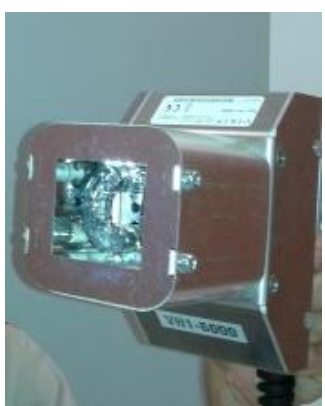

(b)

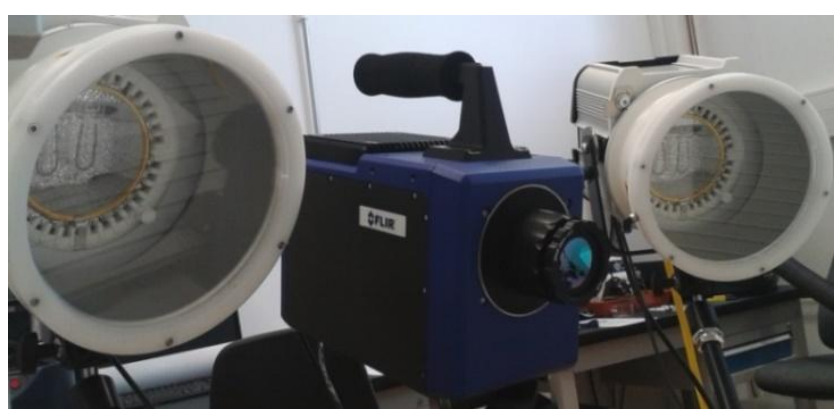

(c)

Fig. 1. Thermal excitation sources - laboratory (a) and industrial (b) flash lamps, halogen lamps (c) 
The three IRNDT analysis methods can be named. The pulse method of IRNDT analysis utilizes thermal excitation by one very short pulse (in the order of $\mathrm{ms}$ ) from flash lamp. During the signal evaluation, time-temperature response is analyzed. There are very short inspection times, limited inspection area, but defects depth can be detected when thermal properties of material are known. The pulse method is suitable for materials with higher thermal diffusivity (the high ability of material to equalize different temperatures.) The transient method of IRNDT analysis (step thermography) exploits thermal excitation by one longer pulse (in the order of seconds) from halogen lamp (or indirect excitation by one ultrasound pulse, for example). The time-temperature response is analyzed during the signal evaluation. There are short inspection times, larger inspection area, detection of defects depth is available. The transient method is recommended to use for material with lower values of thermal diffusivity. The Lock-in method of IRNDT analysis uses a number of pulses from halogen lamps. During the signal evaluation, amplitude or phase shifts are analysed. There are longer inspection times and larger inspection areas. The Lock-in method is suitable for inspection of materials with lower thermal diffusivity.

After the thermal excitation of inspected material, the heat flux spreads inside the material. When the defects (cracks, voids in material, delaminated layers) are present in the material, the heat distribution is affected by these defects. The different heat distribution causes temperature contrast at the material surface. Temperature contrast is measured by IR camera with high sensitivity and further analysed by IRNDT software using a suitable method.

According to the excitation source and infrared measurement positions, the two spatial arrangements of IRNDT analyses are used - reflectance (Fig. 2a,c) and transmittance (Fig. 2b,d) arrangements.
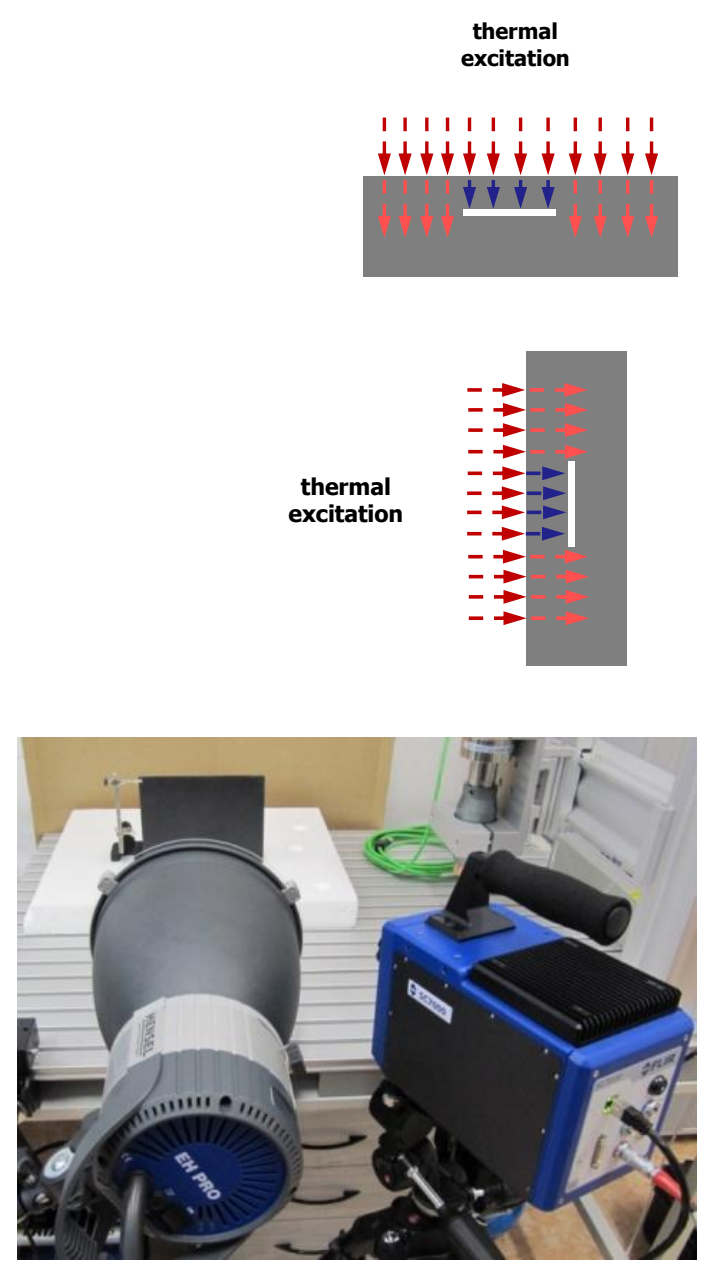

(c)

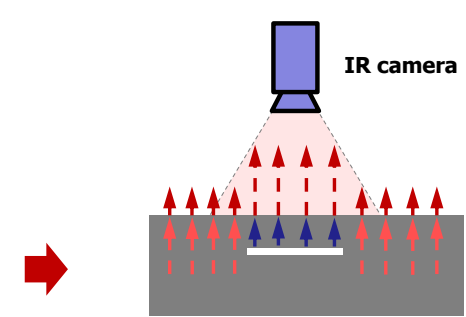

(a)

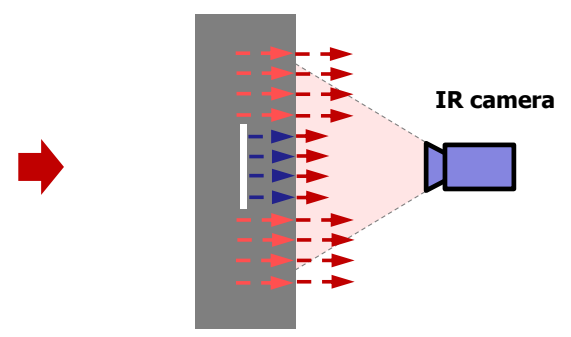

(b)

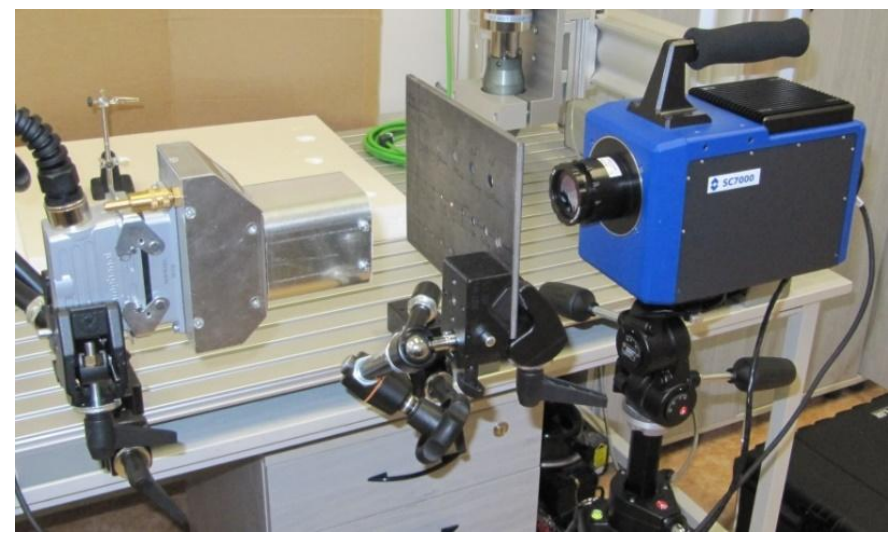

(d)

Fig. 2. Spatial arrangement of excitation source and infrared measurement device positions - reflectance (a) and transmittance (b) arrangement. Reflectance measurement arrangement (c) with laboratory flash lamp used as excitation source, transmittance measurement arrangement (d) with industrial flash lamp 


\subsection{1/qirt.2016.147}

\section{Analyzed samples}

Analyzed samples are in the form of plates from different materials. The defects are made as holes with planar bottoms from the back side of the samples. The holes have specific depths, i.e. distances of their bottoms from the front side of the sample, and diameters. The infrared inspection is performed at the front side of the samples. The selected sample materials cover a wide range of thermal diffusivity.

Thermal diffusivity $a\left(\mathrm{~m}^{2} . \mathrm{s}^{-1}\right)$ is defined by the equation

$$
a=\frac{\lambda}{c \rho},
$$

where $\lambda\left(\mathrm{W} \cdot \mathrm{m}^{-1} \cdot \mathrm{K}^{-1}\right)$ is the thermal conductivity, $c\left(\mathrm{~J} . \mathrm{kg}^{-1} \cdot \mathrm{K}^{-1}\right)$ specific heat capacity and $\rho\left(\mathrm{kg} \cdot \mathrm{m}^{-3}\right)$ density. Thermal diffusivity represents the material ability to equalize different temperatures during non-stationary heat transfer by conduction.
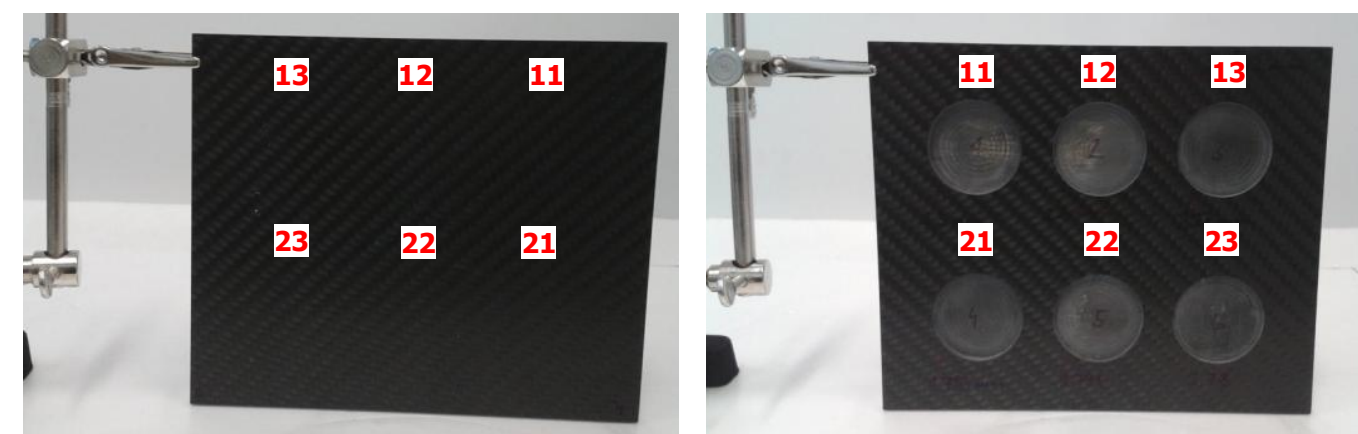

(a)

(b)
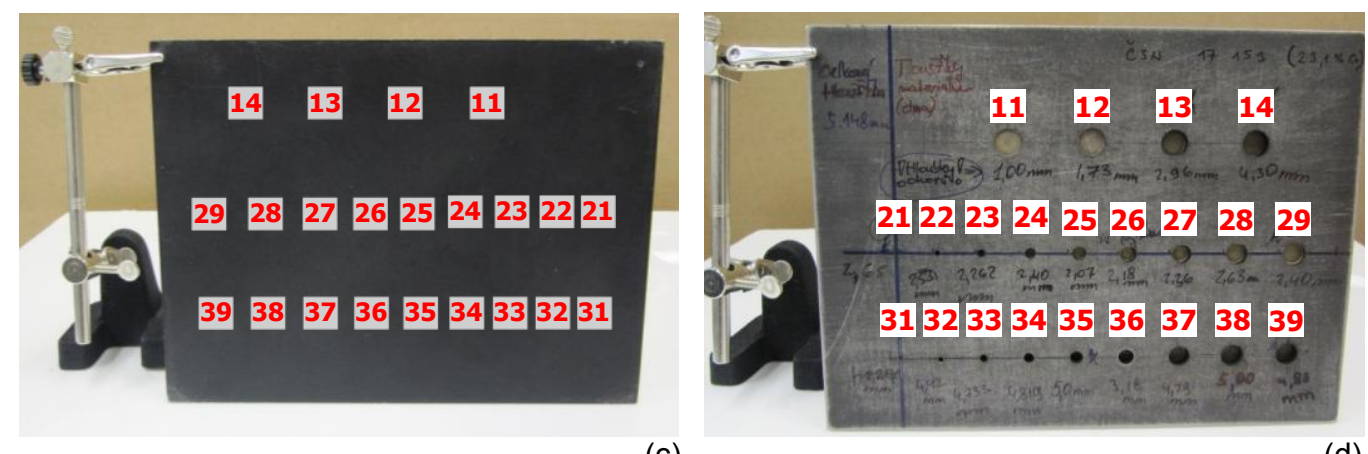

(c)

(d)
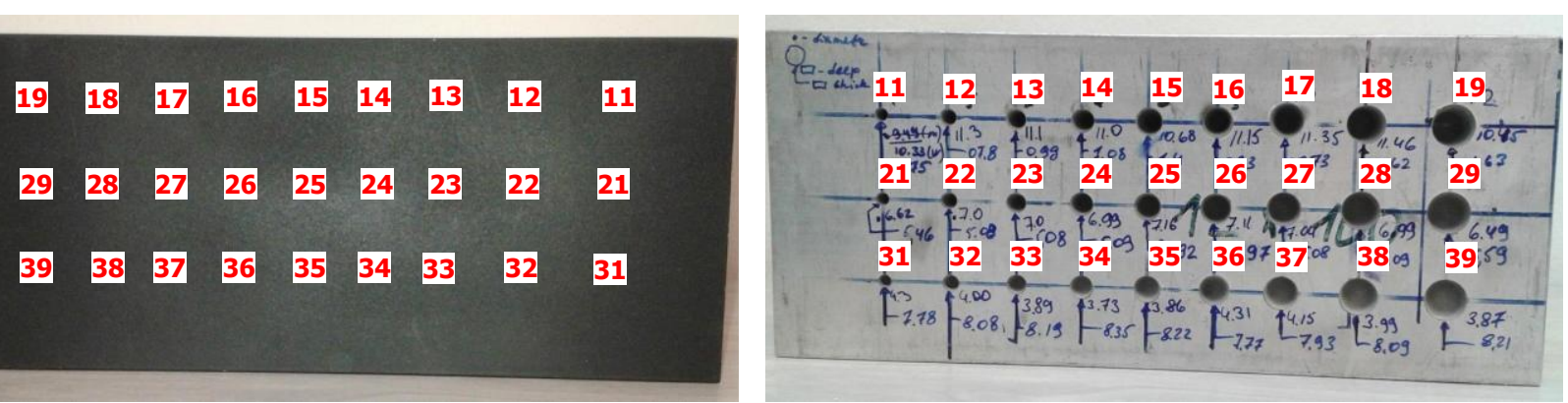

(e)

Fig. 3. Front (a) and back (b) surface of demonstration sample from carbon epoxy composite. Front (c) and back (d) surface of demonstration sample from refractory steel. Front (e) and back (f) surface of demonstration sample from duralumin. There are marked defect's numbers on the front and back sides of the samples 
The carbon epoxy composite sample has a low value of thermal diffusivity $0.2 \mathrm{~m}^{2} . \mathrm{s}^{-1}$. Refractory steel is a material for the sample with medium thermal diffusivity $4.8 \mathrm{~m}^{2} . \mathrm{s}^{-1}$. Duralumin is selected as a material for the sample with higher thermal diffusivity of $50 \mathrm{~m}^{2} . \mathrm{s}^{-1}$. The refractory steel and duralumin samples have the front side (inspected surface) covered by a black high-emissivity coating.

The carbon epoxy composite sample (Fig. 3a,b) is the $144 \times 120 \mathrm{~mm}$ plate of the thickness $5.3 \mathrm{~mm}$ with 6 holes. The holes are arranged to the two rows and have the same diameter of $30 \mathrm{~mm}$. The depths of defects from the inspected side (Fig. 3a) of the sample are between $1.3-3.8 \mathrm{~mm}$.

The refractory steel sample (Fig. 3c,d) is the $200 \times 150 \mathrm{~mm}$ plate of the thickness $5.2 \mathrm{~mm}$ with 22 holes. The holes are arranged to the three rows. The first row -4 defects with diameter approximately $10 \mathrm{~mm}$ and with various depths between $0.85-4.15 \mathrm{~mm}$, the second row -9 defects with depth approximately $2.8 \mathrm{~mm}$ and with various diameters between $0.8-8.9 \mathrm{~mm}$, the third row -9 defects with depth approximately $0.5 \mathrm{~mm}$ and with diameters between $0.8-8.5 \mathrm{~mm}$. The depths of defects are measured from the inspected side (Fig. 3c) of the sample.

The duralumin sample (Fig. 3e,f) is the $230 \times 100 \mathrm{~mm}$ plate of the thickness $12.2 \mathrm{~mm}$ with 27 holes. The holes are arranged to the three rows. The first row - 9 defects with depth approximately $1 \mathrm{~mm}$ and with various diameters between $4.0-12.0 \mathrm{~mm}$, the second row - 9 defects with depth approximately $5.5 \mathrm{~mm}$ and with various diameters between $4.0-12.0 \mathrm{~mm}$, the third row -9 defects with depth approximately $8.0 \mathrm{~mm}$ and with diameters between $4.0-$ $12.0 \mathrm{~mm}$. The depths of defects are measured from the inspected side (Fig. $3 \mathrm{e}$ ) of the sample.

\section{Results and conclusions}

The aim of the IRNDT analyses of the samples were to detect as much defects as possible using pulse, transient and Lock-in methods. The selection of inspection results on carbon epoxy composite sample is showed in Fig. 4. Transient analysis method is used with combination of direct heating by halogen lamps. The reflectance spatial arrangement of excitation source and IR camera is employed. The results are showed for pulse phase evaluation method. Since the power and length of the halogen lamp pulse belong to the excitation parameters, the IRNDT analyses in Fig. 4 are for maximum lamp power and various pulse lengths. Along with the increasing length of pulse, the deeper defects can be detected. Using the $5 \mathrm{~s}$ pulse length (Fig. 4a), the only defects 11 and 21 can be viewed. On contrary, using the very long pulse of $39 \mathrm{~s}$, all the defects are visible in IRNDT analysis (Fig. 4f). As a summary, the large defects in the depth of $3.8 \mathrm{~mm}$ are detectable. The deeper defects as well the defects of smaller size were not prepared on the carbon epoxy composite sample.

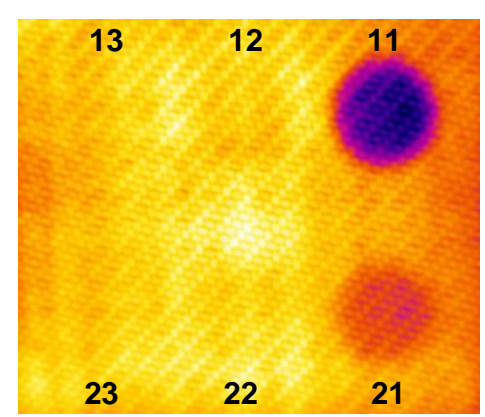

(a)

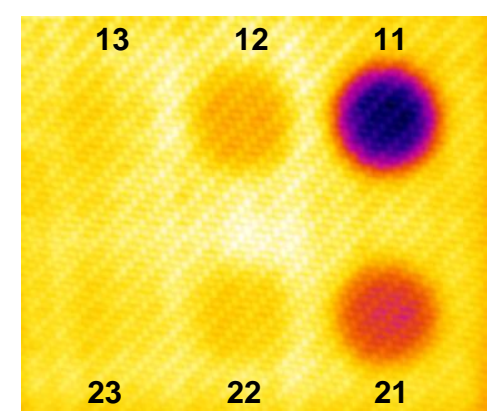

(b)

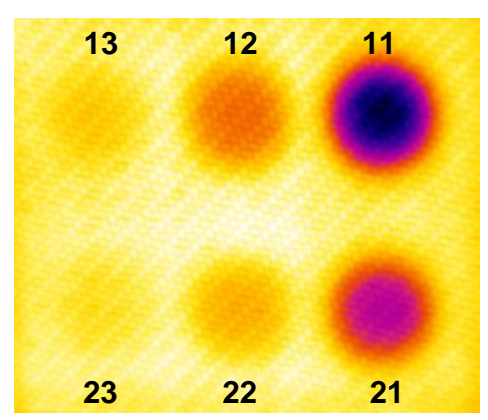

(c)
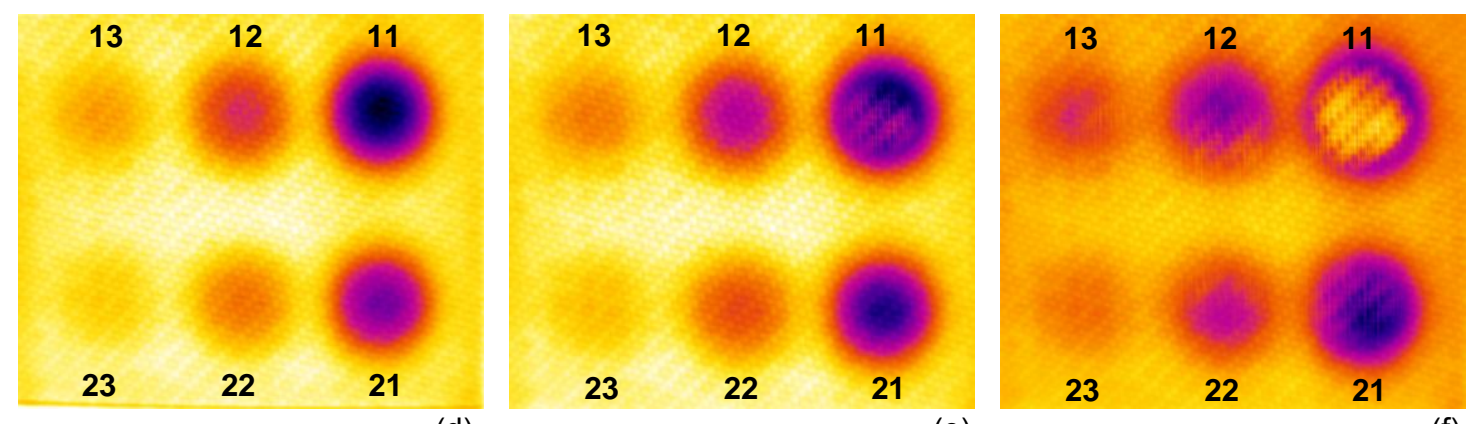

(e)

(f)

Fig. 4. Inspection of defects on the carbon-epoxy composite sample. The length of halogen lamp pulse is the parameter of individual IRNDT evaluations: $5 s(a), 10 s(b), 17 s(c), 26 s(d), 31 s(e)$ and $39 s(f)$ 
The Fig. 5 shows selection of inspection results on refractory steel sample. In the IRNDT inspection, the pulse method of analysis with reflectance measurement arrangement and pulse phase method of evaluation were used. Thermal excitation was provided by laboratory flash lamp with the $1 \mathrm{~ms}$ pulse of maximum power (6 kJ). Performing the IRNDT evaluation at $0.17 \mathrm{~s}$ after the pulse excitation (Fig. $5 \mathrm{a}$ ), the only defects that are near the surface can be detected. Increasing the time of inspection (relatively after the pulse excitation), the deeper and smaller defects can be reached and visualized more and more clearly (see Fig. 5b-f). All IRNDT inspections on Fig. 5a-f were provided using IR camera objective with $25 \mathrm{~mm}$ focal distance. On the Fig. $5 \mathrm{~g}$ is the IRNDT evaluation in the inspection time of $9.80 \mathrm{~s}$ when objective of $50 \mathrm{~mm}$ focal distance was used to reach object surface temperature with better resolution. The Fig. $5 \mathrm{e}, \mathrm{f}$ show the defects 33 and 23 with the diameters of $2.7 \mathrm{~mm}$ in the depths 0.5 and 2.8 respectively. The large defect 11 in the depth $4.2 \mathrm{~mm}$ is clearly distinguishable on the Fig. $5 \mathrm{f}$ at the inspection time $4.95 \mathrm{~s}$. Using the $50 \mathrm{~mm}$ focal distance objective (Fig. $5 \mathrm{~g}$ ), the smaller defect 32 with diameter $1.7 \mathrm{~mm}$ and the depth $0.5 \mathrm{~mm}$ is visible at the inspection time $9.80 \mathrm{~s}$.

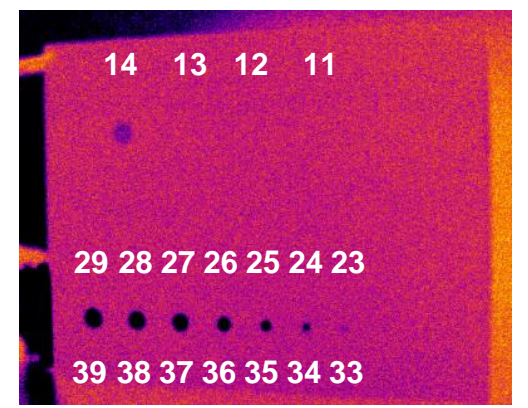

(a)

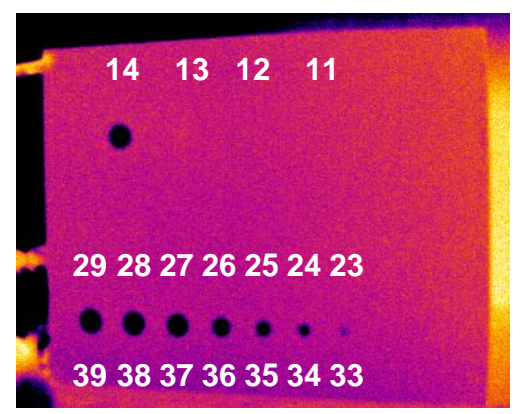

(b)

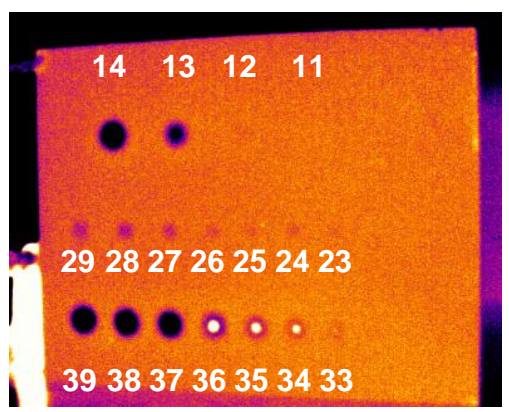

(c)

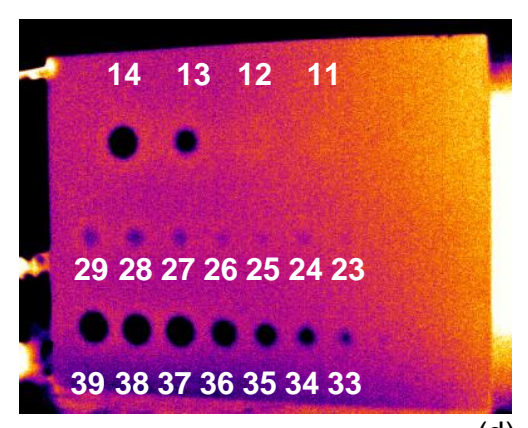

(d)

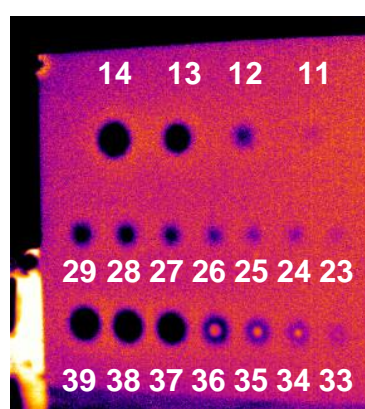

39383736353433

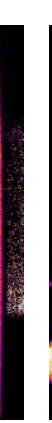

(e)

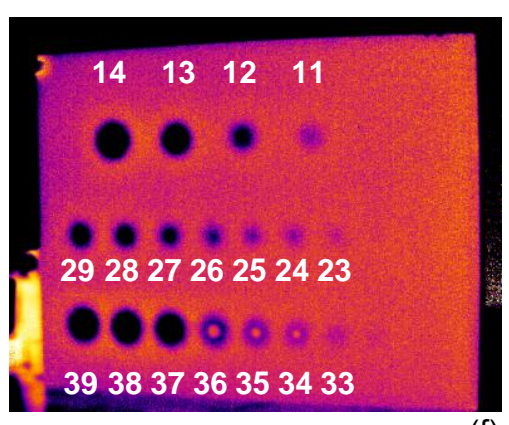

(f)

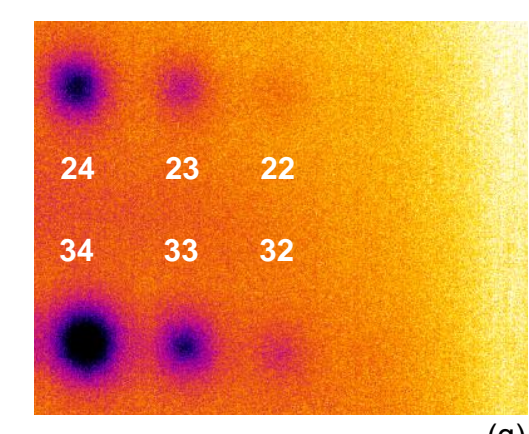

(g)

Fig. 5. Inspection of defects on the refractory steel sample. The time of inspection is the parameter of individual IRNDT evaluations: $0.17 \mathrm{~s}(\mathrm{a}), 0.70 \mathrm{~s}(\mathrm{~b}), 1.88 \mathrm{~s}(\mathrm{c}), 2.47 \mathrm{~s}(\mathrm{~d}), 3.30 \mathrm{~s}(\mathrm{e}), 4.95 \mathrm{~s}(\mathrm{f})$ and $9.80 \mathrm{~s}(\mathrm{~g})$

The selection of inspection results on duralumin sample are summarized in Fig. 6. Pulse method of analysis with reflectance measurement setup were used. Thermal excitation was performed by the flash lamp with maximum power $(6 \mathrm{~kJ})$ and various pulse length between $1-25 \mathrm{~ms}$. The IRNDT inspections in the Fig 6.a-i are fitted to get fine visibility of individual defects. Pulse phase method and root model were used for IRNDT evaluations. The times of inspections were between $0.33-1.67 \mathrm{~s}$ for both types of evaluations. From the first (upper) row of defects that are nearest the surface, the detectable defects were from 19 (Fig. 6a) to 12 (Fig. 6e). Defect no. 12 has the size of $3.7 \mathrm{~mm}$ 
and the depth $0.9 \mathrm{~mm}$ as the smallest detected defect on the duralumin sample. The second (middle) row of defects was not so visible because there are deeper defects in the depth of about $5 \mathrm{~mm}$. The smallest visible defect was no. 26 (Fig. 6i) with the diameter of $7.9 \mathrm{~mm}$ and depth $5.1 \mathrm{~mm}$. The defects from the third (lower) row were not detectable because of their deepest position of about $8 \mathrm{~mm}$.

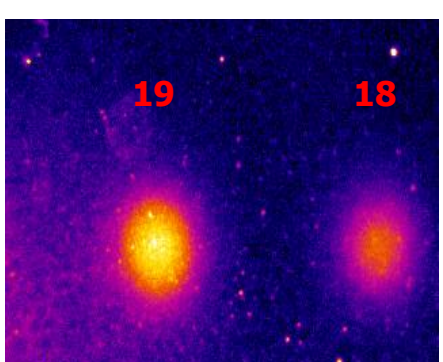

(a)

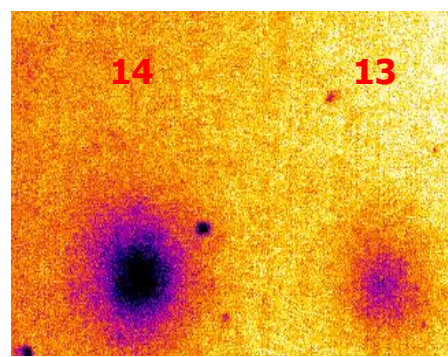

(d)

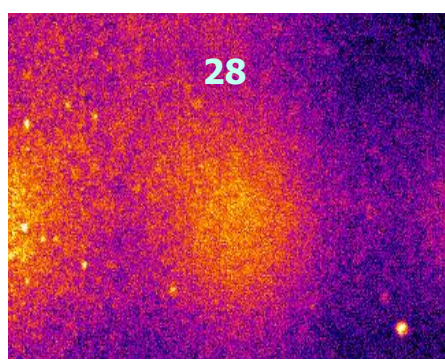

(g)

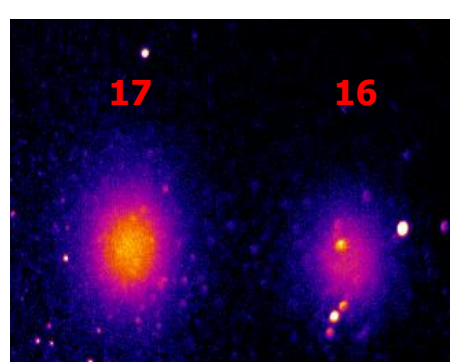

(b)

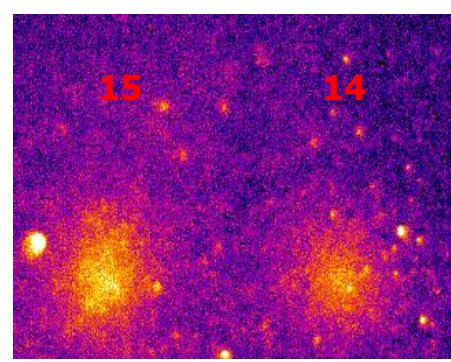

(c)

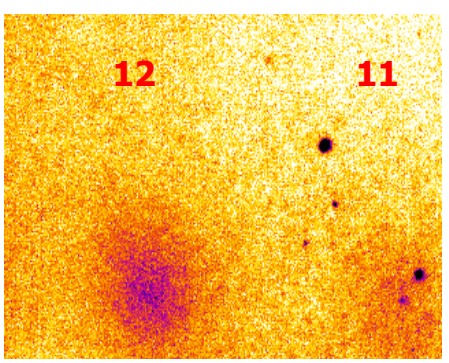

(e)

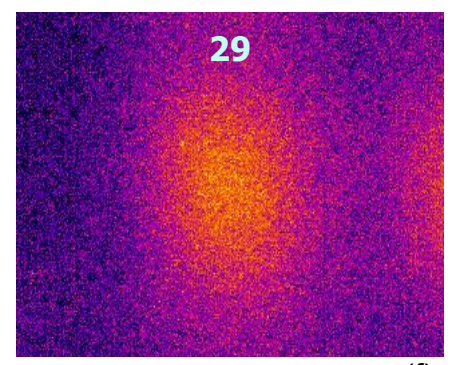

(f)

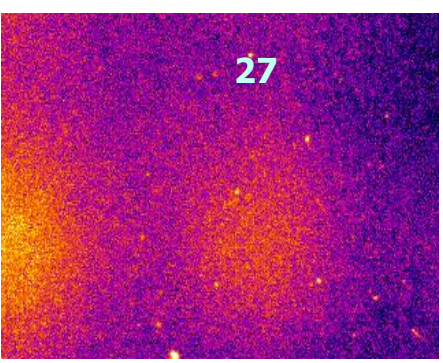

(h)

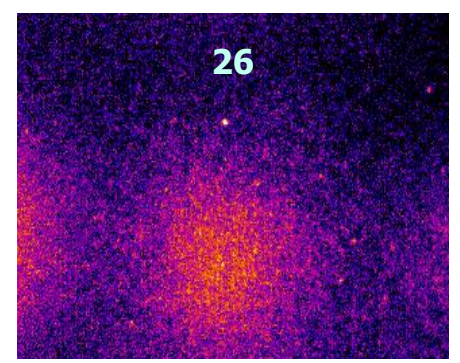

(i)

Fig. 6. Inspection of defects on the duralumin sample. Individual IRNDT evaluations focused on the defects 19-18 (a),17-16 (b), 15-14 (c), 14-13 (d), 12-11(e), 29 (f), 28 (g), 27 (h) and 26 (i)

Increasing the defect depth and/or decreasing the defect diameter, the ability of defects detection rapidly decreases. Already when optimizing the parameters of measurement and evaluation methods, the depth/diameter of defect are restrictive conditions for IRNDT method. However, defect detectability is also influenced by sample thermal properties. For IRNDT method purposes, these thermal properties can be summarized into one parameter called thermal diffusivity. Comparing the detectable defects on analyzed samples, the influence of sample thermal diffusivity is introduced. Tab. 1 shows maximum defects depths (of large defects) and minimum defects sizes (in small depths) that has been detected by IRNDT method. It is evident that increasing the sample thermal diffusivity, the inspection can be performed to a greater depths. The greater thermal diffusivity, the greater depth of sample material is influenced by excitation pulse before it is absorbed. On the other hand, the lower thermal diffusivity is, the smaller defects near the surface can be detected.

Table 1. The effect of thermal diffusivity of sample material on the detectability of defects

\begin{tabular}{|l|l|l|c|}
\hline Thermal diffusivity $\mathbf{a}\left(\mathbf{m}^{2} \cdot \mathbf{s}^{-1}\right)$ & $\mathbf{0 . 2}$ & $\mathbf{4 . 8}$ & $\mathbf{5 0 . 0}$ \\
\hline Maximum detectable depth of (large) defect $(\mathrm{mm})$ & 3.8 & 4.2 & 5.1 \\
\hline Smallest distinguishable defect (in small depth) $(\mathrm{mm})$ & --- & 1.7 & 4.7 \\
\hline
\end{tabular}




\subsection{1/qirt.2016.147}

\section{Acknowledgement}

The result was developed within the CENTEM project, reg. no. CZ.1.05/2.1.00/03.0088, cofunded by the ERDF as part of the Ministry of Education, Youth and Sports OP RDI programme and, in the follow-up sustainability stage, supported through CENTEM PLUS (LO1402) by financial means from the Ministry of Education, Youth and Sports under the "National Sustainability Programme I".

\section{REFERENCES}

[1] Maldague, X., "Theory and Practice of Infrared Technology for Nondestructive Testing", Wiley: New York, USA, 2001.

[2] Vavilov V., "Thermal NDT: historical milestones, state-of-the-art and trends". Quantitative InfraRed Thermography, 2014, Vol.11, No.1, pp. 66-83.

[3] Usamentiaga R., Venegas P., Guerediaga J., Vega L., Molleda J., Bulnes F.G., "Infrared Thermography for Temperature Measurement and Non-Destructive Testing". Sensors, 2014, Vol. 14, pp. 12305-12348.

[4] Montanini R., Aliquò S., " Nondestructive evaluation of plexiglas materials using lock-in and pulse phase infrared thermography". Proceedings of XIX IMEKO World Congress, Fundamental and Applied Metrology, Lisbon, Portugal, 2009, pp. 1524-1529.

[5] Wysocka-Fotek O., Oliferuk W., Maj M., " Reconstruction of size and depth of simulated defects in austenitic steel plate using pulsed infrared thermography". Infrared Physics \& Technology, 2012, Vol. 55, pp. 363-367.

[6] Lahiri B.B., Bagavathiappan S., Reshmi P.R., Philip J., Jayakumar T., Raj B., "Quantification of defects in composites and rubber materials using active thermography". Infrared Physics \& Technology, 2012, Vol. 55, pp. 191-199.

[7] Mulaveesala R., Ghali S.V., "Coded excitation for infrared non-destructive testing of carbon fiber reinforced plastics". Review of Scientific Instruments, 2011, Vol. 82, pp. 054902-01 - 054902-04. 